\title{
Youth Athlete Development and Nutrition
}

\author{
Ben Desbrow' ${ }^{10}$ \\ Accepted: 2 August 2021 / Published online: 13 September 2021 \\ (c) The Author(s) 2021
}

\begin{abstract}
Adolescence (ages 13-18 years) is a period of significant growth and physical development that includes changes in body composition, metabolic and hormonal fluctuations, maturation of organ systems, and establishment of nutrient deposits, which all may affect future health. In terms of nutrition, adolescence is also an important time in establishing an individual's lifelong relationship with food, which is particularly important in terms of the connection between diet, exercise, and body image. The challenges of time management (e.g., school, training, work and social commitments) and periods of fluctuating emotions are also features of this period. In addition, an adolescent's peers become increasingly powerful moderators of all behaviours, including eating. Adolescence is also a period of natural experimentation and this can extend to food choice. Adolescent experiences are not the same and individuals vary considerably in their behaviours. To ensure an adolescent athlete fulfils his/her potential, it is important that stakeholders involved in managing youth athletes emphasize eating patterns that align with and support sound physical, physiological and psychosocial development and are consistent with proven principles of sport nutrition.
\end{abstract}

\section{Key Points}

Advice to developing athletes regarding nutrition should prioritise long-term and sustainable health.

The pathway to elite sports performance is complex and is not dictated by undue emphasis on developing an individual's body composition.

\section{Introduction}

Regular exercise provides many benefits to adolescents, including social interaction, improved physical health, and the development of self-identity and self-esteem. In addition, the second decade of life is an important time in establishing an individual's relationship with food and the lifelong connection between diet, exercise and body image [1]. This

Ben Desbrow

b.desbrow@griffith.edu.au

1 School of Allied Health Sciences, Griffith University, Gold Coast, QLD, Australia narrative review incorporates aspects of physiology, psychology, training science and sociology to describe our current understanding of the nutrition priorities for developing adolescent athletes. Given the pathway to elite adult performance is multifaceted [2] and non-linear (i.e., success at junior levels infrequently predicting elite adult performance [3]), sound nutrition supporting holistic athlete health is of utmost importance during this period. The responsibility for the provision of appropriate nutrition care to developing adolescent athletes is shared among sporting organisations, coaches, parents, teachers and the athletes themselves.

\section{The Changing Focus of Youth Athlete Development}

Adolescence is a period of significant physical development that includes altered body composition, metabolic and hormonal fluctuations, maturation of organ systems and establishment of nutrient deposits, which may all affect future health [4]. Clearly, participation in sport plays an important role in supporting psychological well-being and developing a healthy self-image for most adolescents [5]. However, increased rates of disturbed eating attitudes/behaviours and body dissatisfaction have been evident in sports emphasizing leanness for many years [6-8]. While athletes 
may have intrinsic characteristics (e.g., perfectionism, high pain tolerance and motivation) valued by competitive sport, these qualities may also contribute to the development of disordered eating [9]. Furthermore, external pressures from coaches, peers, parents and social media also influence behaviour [10]. For example, previous findings suggest that careless comments from coaches referencing weight or appearance can precipitate the onset of, or perpetuate, disordered eating or eating disorders in athletes [11]. This evidence, combined with high-profile advocacy from former athletes [12] and a greater appreciation of the longterm health consequences of mismanaging the diet/exercise relationship in adolescent athletes [13], has led to recent calls to fundamentally change how sports manage aspiring athletes [14]. These changes may involve avoiding unwarranted nutrition/food-related discussions, abolishing body composition/weight assessments, raising awareness of the negative effects of chronic low energy availability (LEA), and disrupting toxic training environments featuring abusive body shaming, including the use of training strategies designed to manipulate an athlete's physique independent of performance.

In response, some sporting organisations have attempted to safeguard their custodianship of adolescent athletes by publishing expected stakeholder behaviours. For example, in 2019, Gymnastics Australia released Body Positive Guidelines, providing specific recommendations on appropriate language, the frequency and delivery of nutrition education, and body composition assessment within gymnastic environments [15]. Specifically, the guidelines state that body composition assessments (including weight, height, skinfolds or physique assessments) should only be conducted by an experienced and certified anthropometrist, after education has been provided and written consent from gymnasts and parents/guardians has been obtained. The extent to which such strategies moderate the behaviour of coaches, parents and support staff, and/or ultimately reduce the incidence of undesirable health outcomes in developing athletes, is yet to be elucidated. In the interim, it seems prudent to suggest that those involved in adolescent sport require knowledge and support to ensure appropriate, evidence-based nutrition care is provided to developing athletes.

\section{Energy Needs of Developing Athletes}

Throughout adolescence, adequate energy is required to meet both the growth and development needs of the individual, as well as the substrate demands associated with general physical activity, training and competition
[16]. While group estimates of energy expenditure in adolescent athletes are available (i.e., males $\sim 3640 \pm 830$, females $\sim 3100 \pm 720 \mathrm{kcal} /$ day [17]), the energy expenditure of individual adolescent athletes may vary considerably. Changes in training and competition loads, participation in more than one competitive sport, part-time employment and/or concurrent compensatory sedentary behaviours may all impact energy needs. Determining the individual energy requirements of adolescent athletes is further complicated by metabolic and hormonal variability within and between individuals [18], as well as methodological difficulties in estimating both energy intake and energy expenditure [19].

Growth during puberty is directly related to the hormonal changes that accompany sexual development and is characterised by three phases: (1) minimal height velocity just before the spurt (prepubertal growth lag); (2) peak height velocity (PHV); and (3) decreasing height velocity (epiphyses fuse and final height is achieved) [20]. While girls generally start their growth spurt and attain PHV 2 years earlier than boys ( $\sim 12$ years for girls vs. $\sim 14$ years for boys), other factors such as ethnicity (e.g., individuals with European ancestry $\sim 6$ months younger skeletal age than chronologically matched individuals with Asian and African heritage [21]) may also influence the timing of growth.

The energy needs for growth (a component of the energy requirements of adolescent athletes) consist of two parts: the energy expended to synthesize new tissues, and the energy deposited in growing tissues [22]. The energy expended to synthesize new tissues can be directly measured via the doubly labelled water (DLW) method, or (more commonly) estimated indirectly via measures of resting metabolic rate (RMR). The use of adult-based equations to predict RMR in adolescent athletes is not recommended, as these have been shown to underestimate energy expenditure (up to $300 \mathrm{kcal} /$ day) compared with indirect calorimetry measures [23]. Recently, new predictive resting metabolism equations have been developed from a cohort of male and female junior athletes $(n=126)$ who each undertook an indirect calorimetry assessment of RMR under standardised conditions. The cohort included athletes from a range of sports with an average age of 16.5 years (range 13.1-19.7) [24]. The predictive RMR equation for developing athletes was (Eq. 1):

$$
\begin{aligned}
& \text { RMR }(\mathrm{kcal} / \text { day }) \\
& =11.1 \times \text { Body Mass }(\mathrm{kg})+8.4 \times \text { Height }(\mathrm{cm}) \\
& \quad-(340 \text { male or } 537 \text { female }) .
\end{aligned}
$$

The energy deposited in growing tissues is more difficult to measure but is considered small and is commonly estimated as $\sim 2.0 \mathrm{kcal} / \mathrm{g}$ of daily weight gain (e.g. for a 
15 -year-old male gaining $6 \mathrm{~kg} /$ year $=\sim 33 \mathrm{kcal} / \mathrm{day}$ ) [25]. Hence, while two energy components of growth may alter total caloric requirements, evidence suggests that changes associated with physical activity and/or athletic training are likely to have a much greater influence on total energy demands of adolescent athletes [22].

General energy requirements for adolescent populations with different levels of physical activity and/or training have been published [22]. At the individual level, energy expenditure can be accurately measured using methods such as DLW or via indirect calorimetry. Given these methods are expensive and rely on complex techniques, widely available methods for estimating individual energy expenditures warrant consideration. Published estimates of the specific energy cost of different exercises being undertaken by adolescent athletes do not currently exist. Consequently, the energy expenditure of exercise in adolescents is currently calculated by recording the type, intensity and duration of exercise, and, using the body weight of the individual, computing the energy cost using published adult values of metabolic equivalents (METs) for specific activities [26]. Wearable technologies incorporating accelerometers represent a relatively inexpensive alternative to estimate individual energy expenditure in younger populations. Recent reviews have summarised the validity of different 'wearables' to estimate total energy expenditure and the energy cost of physical activity against DLW [27] and indirect calorimetry [28] in younger (general) populations. These reviews suggest that (1) there is no current ideal device; (2) accelerometers tend to underestimate energy expenditure due to activities such as incline walking, bicycling and carrying items; and (3) more accurate results are recorded when the accelerometer is placed closer to the centre of mass (e.g., hip compared with wrist or ankle) of the individual.

The accurate determination of energy intakes and expenditures is important, as it appears that LEA and potential symptoms of relative energy deficiency in sport (RED-S) in young individuals undertaking heavy training is common $[29,30]$. In developing athletes, LEA may lead to a number of serious health consequences, including delayed puberty, menstrual irregularities, poor bone health, short stature, the development of disordered eating behaviours, and increased risk of injury [31]. Furthermore, in females with a gynecological age of $\leq 14$ years, the effects of LEA may be more pronounced [32]. Conversely, some developing athletes (e.g. in throwing events) demonstrate anthropometric characteristics consistent with chronic disease risk [33]. In this context, severe and prolonged energy restriction is not recommended, with weight maintenance, rather than weight loss, considered a more appropriate management strategy in developing individuals [1].

\section{Macronutrient Needs of Developing Athletes}

\subsection{Protein}

Adolescents require protein to support general growth and development [16], in addition to enhancing the response to exercise training [34]. During peak growth, increases in lean body mass can reach $\sim 2.3 \mathrm{~g} /$ day in females and $\sim 3.8 \mathrm{~g} /$ day in males, which represents an approximately threefold increase from the prepubertal period [35]. In addition, longitudinal data indicate that physically active youth accrue greater increases in lean body mass than their sedentary peers [36]. While regular training does not appear to influence protein turnover in early adolescence [37], one proposed explanation for the enhanced lean mass deposition observed during puberty relates to enhanced anabolic sensitivity (i.e., a greater efficiency of dietary protein utilisation) [38]. This theory has received further support by the recent demonstration that adolescents (males and females) had a greater wholebody net balance when provided with small to optimal amounts of post-exercise protein than weight-stable adults [39]. Furthermore, an increased efficiency of amino acid use would explain previous nitrogen-balance studies that did not demonstrate additional dietary protein intakes were required in adolescent sprint athletes to maintain a positive nitrogen balance during their peak growth phase [40]. Total energy intake is an important consideration in the assessment of protein requirements. With suboptimal energy intake, endogenous protein is mobilised, as well as liver glycogen, to maintain homeostasis of blood glucose, potentially reducing the availability of protein for its primary functions [41]. Provided adequate energy is being consumed, it appears that protein recommendations to maximise whole-body net balance after exercise are primarily influenced by total body and fat-free mass. Protein intake at $\sim 0.11 \mathrm{~g} / \mathrm{kg} / \mathrm{h}$ during post-exercise recovery, or the equivalent of $\sim 1.5 \mathrm{~g} / \mathrm{kg} /$ day (e.g. $\sim 0.3 \mathrm{~g}$ protein $/ \mathrm{kg} \times 5$ meal times), should be sufficient to replace any exerciseinduced amino acid oxidative losses, enhance whole body net protein balance, and support the normal growth and development of adolescent athletes [39, 40].

\subsection{Carbohydrate}

The duration and intensity of exercise sessions determines carbohydrate (CHO) utilisation patterns and refuelling requirements [42]. In addition, the availability of exogenous and endogenous $\mathrm{CHO}$ influences exercise-mediated training adaptations [43]. Existing evidence suggests that 
the utilisation of $\mathrm{CHO}$ in adolescents does not differ substantially from that of adults (for review see Desbrow and Leveritt [44]). While the impact of developmental age on CHO-mediated training adaptations remains unclear, a reduced capacity to adapt to changes in $\mathrm{CHO}$ availability observed in obese versus non-obese adults [45] also appears evident in those aged 8-17 years [46]. The mechanisms underpinning the ergogenic effect of $\mathrm{CHO}$ in adults are metabolic (i.e., substrate provision), and centrally derived (i.e., CHO signalling in the oral cavity) [47]. To date, no study has assessed the impact of centrally mediated $\mathrm{CHO}$ effects in adolescent athletes.

Dietary CHO needs should be considered in light of the training loads and competition characteristics that are typically undertaken by adolescent athletes. These can differ from those undertaken by adult athletes in a number of ways. First, adolescent athletes may be involved with numerous organisations (e.g., schools, clubs and regions) creating different competition frequencies and formats, such as sports carnivals, representative events and trials. It is also common for aspiring adolescent athletes to participate in a number of different sports. These different energy demands and subsequent $\mathrm{CHO}$ requirements must be considered, particularly when the participation in different sports is concurrent.

During short bouts of exercise (i.e. $<1 \mathrm{~h}$ in duration), a $\mathrm{CHO}$ mouth rinse or small amounts of $\mathrm{CHO}$ may benefit performance, particularly if the athlete has not eaten prior to the exercise. During more prolonged physical activity, a single $\mathrm{CHO}$ source (i.e., glucose) can be oxidised at rates up to $\sim 0.6 \mathrm{~g} / \mathrm{kg} / \mathrm{h}$ in young boys, suggesting a 12-year-old male with a bodyweight of $45 \mathrm{~kg}$ could utilise $\sim 30 \mathrm{~g}$ of $\mathrm{CHO} / \mathrm{h}$ from dietary sources. While dietary strategies incorporating the use of refined $\mathrm{CHO}$ to manipulate metabolism during endurance sport (e.g., CHO loading and/or multiple transportable forms of $\mathrm{CHO}$ throughout exercise) are likely to improve performance in events of $>90$ min duration [48], these recommendations should only be employed in relevant situations, which are less likely for adolescent athletes given the shorter duration of many events.

\subsection{Fat}

Adequate dietary fat intake is needed to meet the requirements for fat-soluble vitamins and essential fatty acids, and helps to provide energy to support growth and maturation [18]. In addition, evidence suggests that maximal fat oxidation rates (relative to lean mass) appear slightly higher in athletes $<18$ years [49]. To date, dietary strategies promoting the role of the intramuscular triacylglycerols on performance and the effect of training in a CHO-depleted state on adolescent endurance athletes remains unstudied. Since chronically high fat intakes are associated with increased chronic disease risk, the recommendation for type and total fat intake by adolescent athletes remains in accordance with public health guidelines. Typically, these guidelines suggest a dietary fat intake of $20-35 \%$ of total energy, with saturated trans fatty acids providing no more than $10 \%$ of total energy intake [50, 51].

When energy demands change, sports nutrition recommendations encourage athletes to manipulate dietary intake to support daily performance and optimise adaptations to training [52], a concept known more commonly as 'fuel for the work required' [53]. Adolescent athletes are likely to require support to develop a 'food first' approach to matching energy intakes with increased training loads and may benefit from practical resources translating changes in macronutrient needs to food selection [54].

\section{Micronutrient Needs for Adolescent Athletes}

\subsection{Iron}

Depleted iron stores, without clinical symptoms, are observed frequently in studies conducted on adolescent athletes (particularly endurance competitors) $[55,56]$. However, interpreting one-off measures of iron status markers (e.g., serum ferritin) in developing athletes should be done with caution for several reasons: cut-off values for ferritin are not standardised in studies of youth athletes; athletes generally have lower levels of ferritin than non-athletes; sex differences are evident between males and females during adolescence; and ferritin levels can be falsely positive in mild infection, injury or physiological stress [57].

Detection and early treatment of iron depletion in adolescent athletes is nonetheless warranted. This is because growth increases iron requirements in adolescents compared with older athletes, resulting in the progression from low iron stores to a state of iron deficiency being rapid. Reference values (Table 1) [58] and strategies to address poor iron status in athletes [59] have been established.

In terms of performance, even mild tissue decrements in iron have the potential to adversely affect endurance capacity and aerobic adaptation to training [60]. Indeed, a recent study involving over 70 adolescent female athletes indicated a moderate relationship between athletic performance, the concentration of soluble transferrin receptors, and dietary iron intake, emphasizing the importance of iron intake for aspiring adolescent female athletes [61].

In adolescent female endurance athletes, suboptimal iron status is mainly attributed to low iron intake and low iron bioavailability in combination with high requirements associated with training and blood loss (e.g., increased red cell mass, menstruation, haematuria, haemolysis) $[62,63]$. In contrast, suboptimal iron status in adolescent 
Table 1 Definition and assessment of stages of iron deficiency [58]

\begin{tabular}{llll}
\hline Stage & 1. Depleted iron stores & 2. Early functional iron deficiency & 3. Iron deficiency anaemia \\
\hline Description & $\begin{array}{l}\text { Iron stores in the bone marrow, liver, } \\
\text { and spleen are depleted }\end{array}$ & $\begin{array}{c}\text { Erythropoiesis diminishes as the iron supply to } \\
\text { the erythroid marrow is reduced }\end{array}$ & $\begin{array}{c}\text { Haemoglobin produc- } \\
\text { tion falls, resulting in } \\
\text { anaemia }\end{array}$ \\
& $\mathrm{SF}<35 \mu \mathrm{g} / \mathrm{L}$ & $\mathrm{SF}<20 \mu \mathrm{g} / \mathrm{L}$ & $\mathrm{SF}<12 \mu \mathrm{g} / \mathrm{L}$ \\
Assessment & $\mathrm{Hb}>115 \mathrm{~g} / \mathrm{L}$ & $\mathrm{HS}<115 \mathrm{~g} / \mathrm{L}$ & $\mathrm{Hb}<115 \mathrm{~g} / \mathrm{L}$ \\
& $\mathrm{TS}>16 \%$ & $\mathrm{TS}<16 \%$ & \\
\hline
\end{tabular}

$S F$ serum ferritin, $H b$ haemoglobin, $T S$ transferrin saturation

male athletes is associated more with high physiological requirements (i.e., training and growth) than with diet. Recommendations for iron for developing girls account for iron lost from menstruation. While often a population reference value is used as an age cut-off for menarche (e.g. 14 years), individual recommendations should be adjusted when individual differences exist (particularly when menarche occurs earlier). It is possible that vegetarian athletes have increased requirements due to low iron bioavailability of non-haem iron sources. However, scientific advisory summaries indicate that when comparing vegetarians with non-vegetarians, most studies demonstrate no significant differences in dietary iron intake or haemoglobin concentrations. Although serum ferritin concentrations are consistently statistically significantly lower in vegetarians, they are usually within the reference ranges [64]. That said, it seems prudent to ensure adolescent vegetarian athletes monitor iron status routinely.

\subsection{Calcium}

Lifespan calcium requirements are highest during the pubertal growth spurt. The rate of skeletal calcium accretion during adolescence is estimated to be around $300 \mathrm{mg} /$ day [65]. There are currently no specific recommendations for calcium intake for athletes, therefore, until further studies are undertaken, population reference standards can be used as a benchmark for assessing adequacy. Calcium recommendations are based on estimates of urinary and sweat losses and assume a net calcium absorption from food (often $\sim 25-35 \%$ ). Recommendations for adolescents vary between regions, with values ranging from $800 \mathrm{mg} /$ day (e.g., UK females aged 15-18 years) to $1300 \mathrm{mg} /$ day (US, Canada, Australia for males and females aged 14-18 years). High-intensity weight-bearing exercise and, to some extent, resistance exercise, increase bone mineral content in exercising adolescents. [66-68]. While this effect is small (typically $<6 \%$ difference) and unlikely to increase calcium requirements, enhanced bone mineral content may maximise peak hip strength and prevent osteoporosis in later life.

\subsection{Vitamin D}

While vitamin D is best known for its role in bone health, it has many functions in other physiological systems (e.g., immune system, muscular system). Vitamin D insufficiency is also linked to skeletal muscle function, muscle pain and weakness, and inflammation, and may potentially increase susceptibility to injury and slow rate of rehabilitation from injury (for review see de la Puente Yague et al. [69]). Hence, vitamin D status (particularly in adult athletes) has received considerable recent scientific attention. Currently, the influence of vitamin D status and the benefits of supplementation in youth athletes identified as deficient remain largely unknown. However, recent prospective studies suggest little correlation between serum levels of 25 hydroxyvitamin $\mathrm{D}$ and sports performance in adolescent athletes [70], even when vitamin D deficiencies are corrected [71].

Similar to adult athletes, developing athletes are at high risk of vitamin $\mathrm{D}$ deficiency if they have experienced limited sun exposure (e.g., reside in latitudes $>35^{\circ}$, spend long periods training indoors, have dark skin, use sunscreen or wear protective clothing). Typically, fixed amounts of vitamin $\mathrm{D}$ are recommended beyond infancy, until values for older adults are further increased to account for the reduced capacity of the skin to produce vitamin D with ageing. Recommendations for vitamin D differ by region (Australia $=5 \mu \mathrm{g}$ / day, US/Canada $=15 \mu \mathrm{g} /$ day, European countries range from 10 to $20 \mu \mathrm{g}$ /day). However, all authorities agree that monitoring of 25 hydroxyvitamin $\mathrm{D}$ is important for at-risk groups.

\section{Fluid Needs of Developing Athletes}

Young individuals appear to have similar capacity to adults to deal with thermal loads and exercise tolerance time during exercise in the heat $[72,73]$; however, the mechanisms by which young individuals dissipate heat loads during exercise differ from those of adults [73, 74]. Children and adolescents appear to rely more on peripheral blood redistribution (radiative and conductive cooling) rather than sweating (evaporative cooling) to maintain thermal equilibrium [74, 
75]. There is also evidence that adolescents who undertake regular training adapt by enhanced peripheral vasodilation [76], which is likely to improve non-evaporative cooling. While the timing of the transition from child-like to adultlike thermoregulatory mechanism is likely to be related to pubertal development, it appears that these changes do not become physiologically evident until puberty has been completed [77].

There is some evidence suggesting an increased prevalence of heat illness associated with sport and activity in youth athletes [78]. Heat illness may be influenced by poor hydration status along with other factors such as undue physical exertion, insufficient cooling between exercise bouts and inappropriate choices of clothing, including uniforms. Unfortunately, there is no evidence to determine the extent to which (if at all) fluid intake may modulate the risk of heat illness in adolescent athletes. This is because fluid monitoring studies on children and adolescents at risk of heat illness are scarce and often fail to report participants who actually experience heat illnesses [79]. In contrast, field studies [80] and large cohort investigations [75] indicate that trained adolescent athletes can experience significant deficits in fluid ( $>4 \%$ body weight) and high sweat rates $(\leq 2.16 \mathrm{~L} / \mathrm{h})$, respectively, in response to exercise. Fluid shifts of this magnitude have the potential to induce signs/symptoms of hypohydration and affect exercise performance. Consequently, fluid intake guidelines for young athletes $[81,82]$ are similar to those recommended for adults [83]. This advice includes commencing exercise well-hydrated, developing individualised drinking plans (refined regularly during puberty to accommodate changes in sweat rate), limiting body mass losses during activity to $\leq 2 \%$ from pre-exercise values and avoiding weight gain. In general, fluid intakes of $13 \mathrm{~mL} / \mathrm{kg}$ per hour of exercise should be sufficient to avoid significant fluid deficits in developing athletes [82].

Finally, developing athletes may not recognise the signs or symptoms of heat stress, forget to drink unless reminded and continue to exercise to keep up with their peers. Therefore, it is important that when environmental and contextual factors (e.g., intensity/duration of exercise, clothing, fluid availability) combine to increase thermoregulatory risks, strategies to moderate metabolic heat loads in adolescent athletes should be implemented proactively.

\section{Dietary Supplements and Ergogenic Aid Use by Developing Athletes}

The judicious use of specific dietary supplements and nutritional ergogenic aids may improve sporting performance in adults [84]. However, most (but not all [85]) products are yet to have their effectiveness and long-term safety rigorously explored in younger populations, often due to the ethical principle of beneficence (i.e. cost vs. benefit). Despite the paucity of scientific evidence, reported supplement use with the intent to improve sports performance among youth athletes is common $[86,87]$. The prevalence of supplement use among US children and adolescents ( $<18$ years) as a performance enhancer was $1.6 \%$ [86]. Vitamin/mineral supplements, sports/protein powders, vitamin waters, creatine and caffeine are commonly identified as popular supplements used by adolescent athletes [88].

Adolescent athletes take 'performance-enhancing' dietary supplements for several reasons, such as pressure to achieve results, the pursuit of physical ideals, and peer, social and marketing pressure. Furthermore, while some elite adolescent athletes do not believe that dietary supplements are required to be successful in their sport, they still consider them important for certain training adaptations, such as strength gains [89].

Generally, it is considered inappropriate for young athletes to be encouraged to consume dietary supplements for performance enhancement. This view is consistent with those of leading sporting organisations and expert groups [90-92]. This recommendation excludes the clinical use of dietary supplements (e.g., calcium, iron, vitamin D) when taken under appropriate guidance from suitably qualified health professionals (e.g., a medical practitioner, sports dietitian). Developing athletes have the potential for large performance gains through maturation and experience in their sport, along with adherence to proper training, nutrition and rest regimens. Apart from issues related to safety, the use of legal supplements in developing athletes over-emphasizes their ability to manipulate performance (i.e., typically $2-5 \%$ improvement [84]). Prioritising prudent training and whole food-based nutrition practices in adolescent athletes has been emphasized, even when safe supplements are being considered [85].

\section{Conclusion}

Adolescent athletes have unique nutritional requirements as a consequence of undertaking daily training and competition in addition to the demands of growth and development. Dietary education and recommendations for this group of athletes should reinforce eating for long-term health. More specifically, the developing athlete should be encouraged to moderate eating patterns to reflect daily exercise demands and provide a regular spread of highquality $\mathrm{CHO}$ and protein sources over the day, especially in the period immediately after training. Particular consideration should also be given to the potential risk of LEA and also to dietary calcium, vitamin D and iron intake of youth athletes because of the risk of deficiency and high requirements. The nutrient needs of adolescent athletes 
should be met by food rather than supplements. The use of dietary supplements by developing athletes over-emphasizes their ability to manipulate performance in comparison with other training and dietary strategies.

Acknowledgements This supplement is supported by the Gatorade Sports Science Institute (GSSI). The supplement was guest edited by Lawrence L. Spriet, who convened a virtual meeting of the GSSI Expert Panel in October 2020 and received honoraria from the GSSI, a division of PepsiCo, Inc., for his participation in the meeting. Dr Spriet received no honoraria for guest editing the supplement. Dr Spriet suggested peer reviewers for each paper, which were sent to the Sports Medicine Editor-in-Chief for approval, prior to any reviewers being approached. Dr Spriet provided comments on each paper and made an editorial decision based on comments from the peer reviewers and the Editor-in-Chief. Where decisions were uncertain, Dr Spriet consulted with the Editor-in-Chief. The views expressed in this manuscript are those of the authors and do not necessarily reflect the position or policy of PepsiCo, Inc.

\section{Declarations}

Funding This article is based on a presentation by the author to the GSSI Expert Panel Virtual Meeting in October 2020. An honorarium for preparation of this article was provided by the GSSI. No other sources of funding were used to assist in the preparation of this article.

Conflict of interests Ben Desbrow has no conflicts of interest relevant to the content of this article. This review was completed at the paid request of the Gatorade Sports Science Institute.

Open Access This article is licensed under a Creative Commons Attribution 4.0 International License, which permits use, sharing, adaptation, distribution and reproduction in any medium or format, as long as you give appropriate credit to the original author(s) and the source, provide a link to the Creative Commons licence, and indicate if changes were made. The images or other third party material in this article are included in the article's Creative Commons licence, unless indicated otherwise in a credit line to the material. If material is not included in the article's Creative Commons licence and your intended use is not permitted by statutory regulation or exceeds the permitted use, you will need to obtain permission directly from the copyright holder. To view a copy of this licence, visit http://creativecommons.org/licenses/by/4.0/.

\section{References}

1. Desbrow B, McCormack J, Burke LM, Cox GR, Fallon K, Hislop M, et al. Sports Dietitians Australia position statement: sports nutrition for the adolescent athlete. Int J Sport Nutr Exerc Metab. 2014;24(5):570-84. https://doi.org/10.1123/ijsnem. 2014-0031.

2. Mills A, Butt J, Maynard I, Harwood C. Identifying factors perceived to influence the development of elite youth football academy players. J Sports Sci. 2012;30(15):1593-604. https:// doi.org/10.1080/02640414.2012.710753.

3. Pizzuto F, Bonato M, Vernillo G, La Torre A, Piacentini MF. Are the World Junior Championship finalists for middle- and long-distance events currently competing at international level? Int J Sports Physiol Perform. 2017;12(3):316-21. https://doi. org/10.1123/ijspp.2015-0717.
4. Sawyer SM, Afifi RA, Bearinger LH, Blakemore SJ, Dick B, Ezeh AC, et al. Adolescence: a foundation for future health. Lancet. 2012;379(9826):1630-40. https://doi.org/10.1016/ S0140-6736(12)60072-5.

5. Ekeland E, Heian F, Hagen KB. Can exercise improve self esteem in children and young people? A systematic review of randomised controlled trials. Br J Sports Med. 2005;39(11):792-8. https://doi. org/10.1136/bjsm.2004.017707 (discussion 792-8).

6. Torstveit MK, Rosenvinge JH, Sundgot-Borgen J. Prevalence of eating disorders and the predictive power of risk models in female elite athletes: a controlled study. Scand J Med Sci Sports. 2008;18(1):108-18. https://doi.org/10.1111/j.1600-0838.2007. 00657.x.

7. Ferrand C, Magnan C, Philippe RA. Body-esteem, body mass index, and risk for disordered eating among adolescents in synchronized swimming. Percept Mot Skills. 2005;101(3):877-84.

8. Martinsen M, Bratland-Sanda S, Eriksson AK, Sundgot-Borgen J. Dieting to win or to be thin? A study of dieting and disordered eating among adolescent elite athletes and non-athlete controls. Br J Sports Med. 2010;44(1):70-6. https://doi.org/10. 1136/bjsm.2009.068668.

9. Stirling A, Kerr G. Perceived vulnerabilities of female athletes to the development of disordered eating behaviours. Eur J Sport Sci. 2012;12(3):262-73. https://doi.org/10.1080/17461391. 2011.586437.

10. Stoyel H, Delderfield R, Shanmuganathan-Felton V, Stoyel A, Serpell L. A qualitative exploration of sport and social pressures on elite athletes in relation to disordered eating. Front Psychol. 2021. https://doi.org/10.3389/fpsyg.2021.633490.

11. Stoyel H, Slee A, Meyer C, Serpell L. Systematic review of risk factors for eating psychopathology in athletes: a critique of an etiological model. Eur Eat Disord Rev. 2020;28(1):3-25. https:// doi.org/10.1002/erv.2711.

12. Cain M. I was the fastest girl in America, until I joined Nike. New York: NY Times; 2019.

13. Mountjoy M, Sundgot-Borgen J, Burke L, Carter S, Constantini $\mathrm{N}$, Lebrun $\mathrm{C}$, et al. The IOC consensus statement: beyond the female athlete triad-relative Energy Deficiency in Sport (REDS). Br J Sports Med. 2014;48(7):491-7. https://doi.org/10.1136/ bjsports-2014-093502.

14. Ackerman KE, Stellingwerff T, Elliott-Sale KJ, Baltzell A, Cain M, Goucher K, et al. \#REDS (Relative Energy Deficiency in Sport): time for a revolution in sports culture and systems to improve athlete health and performance. Br J Sports Med. 2020;54(7):369-70. https://doi.org/10.1136/bjspo rts-2019-101926.

15. Gymnastics, Australia. Body Positive Guidelines. 2019 [cited Feb 2021]. https://www.gymnastics.org.au/Ga/Athletes/Body_ Positive.aspx. Accessed 18 Aug 2021.

16. Aerenhouts D, Deriemaeker P, Hebbelinck M, Clarys P. Energy and macronutrient intake in adolescent sprint athletes: a followup study. J Sports Sci. 2011;29(1):73-82.

17. Carlsohn A, Scharhag-Rosenberger F, Cassel M, Weber J, de Guzman GA, Mayer F. Physical activity levels to estimate the energy requirement of adolescent athletes. Pediatr Exerc Sci. 2011;23(2):261-9.

18. Petrie H, Stover E, Horswill C. Nutritional concerns for the child and adolescent competitor. Nutrition. 2004;20:620-31.

19. Burke LM, Cox GR, Culmmings NK, Desbrow B. Guidelines for daily carbohydrate intake: do athletes achieve them? Sports Med. 2001;31(4):267-99.

20. Karlberg J. On the construction of the infancy-childhoodpuberty growth standard. Acta Paediatr Scand Suppl. 1989;356:26-37.

21. Grgic O, Shevroja E, Dhamo B, Uitterlinden AG, Wolvius EB, Rivadeneira F, et al. Skeletal maturation in relation to ethnic 
background in children of school age: the Generation R Study. Bone. 2020;132:115180. https://doi.org/10.1016/j.bone.2019. 115180.

22. Torun B. Energy requirements of children and adolescents. Public Health Nutr. 2005;8(7A):968-93.

23. Loureiro LL, Fonseca S Jr, Castro NG, Dos Passos RB, Porto CP, Pierucci AP. Basal metabolic rate of adolescent modern pentathlon athletes: agreement between indirect calorimetry and predictive equations and the correlation with body parameters. PLoS ONE. 2015;10(11):e0142859. https://doi.org/10.1371/journal. pone. 0142859 .

24. Reale RJ, Roberts TJ, Lee KA, Bonsignore JL, Anderson ML. Metabolic rate in adolescent athletes: The development and validation of new equations, and comparison to previous models. Int J Sport Nutr Exerc Metab. 2020;30(4):249-57. https://doi.org/10. 1123/ijsnem.2019-0323.

25. World Health Organization. Measuring change in nutritional status. Geneva: World Heath Organization; 1983.

26. Ainsworth B. How to assess the energy costs of exercise and sport. In: Maughan R, editor. Sports nutrition. 2nd ed. IOC Medical Commission; 2014. p. 61-71.

27. Sardinha LB, Judice PB. Usefulness of motion sensors to estimate energy expenditure in children and adults: a narrative review of studies using DLW. Eur J Clin Nutr. 2017;71(8):1026. https://doi. org/10.1038/ejen.2017.78.

28. Lynch BA, Kaufman TK, Rajjo TI, Mohammed K, Kumar S, Murad MH, et al. Accuracy of accelerometers for measuring physical activity and levels of sedentary behavior in children: a systematic review. J Prim Care Community Health. 2019;10:1-8. https://doi.org/10.1177/2150132719874252.

29. Muia EN, Wright HH, Onywera VO, Kuria EN. Adolescent elite Kenyan runners are at risk for energy deficiency, menstrual dysfunction and disordered eating. J Sports Sci. 2016;34(7):598-606. https://doi.org/10.1080/02640414.2015.1065340.

30. Rogers MA, Appaneal RN, Hughes D, Vlahovich N, Waddington G, Burke LM, et al. Prevalence of impaired physiological function consistent with Relative Energy Deficiency in Sport (RED$\mathrm{S})$ : an Australian elite and pre-elite cohort. Br J Sports Med. 2021;55(1):38-45. https://doi.org/10.1136/bjsports-2019-101517.

31. Desbrow B, Burd NA, Tarnopolsky M, Moore DR, Elliott-Sale KJ. Nutrition for special populations: young, female, and masters athletes. Int J Sport Nutr Exerc Metab. 2019;29(2):220-7. https:// doi.org/10.1123/ijsnem.2018-0269.

32. Loucks AB. The response of luteinizing hormone pulsatility to 5 days of low energy availability disappears by 14 years of gynecological age. J Clin Endocrinol Metab. 2006;91(8):3158-64. https://doi.org/10.1210/jc.2006-0570.

33. Hirsch KR, Smith-Ryan AE, Trexler ET, Roelofs EJ. Body composition and muscle characteristics of Division I track and field athletes. J Strength Cond Res. 2016;30(5):1231-8. https://doi.org/ 10.1519/JSC.0000000000001203.

34. Witard O, Garthe I, Phillips S. Dietary protein for training adaptation and body composition manipulation in track and field athletes. Int J Sport Nutr Ex Metab. 2019;29:165-74.

35. Forbes GB. Growth of the lean body mass during childhood and adolescence. J Pediatrics. 1964;64:822-7. https://doi.org/10.1016/ s0022-3476(64)80640-5.

36. Baxter-Jones AD, Eisenmann JC, Mirwald RL, Faulkner RA, Bailey DA. The influence of physical activity on lean mass accrual during adolescence: a longitudinal analysis. J Appl Physiol (1985). 2008;105(2):734-41. https://doi.org/10.1152/japplphysi ol.00869.2007.

37. Boisseau N, Persaud C, Jackson AA, Poortmans JR. Training does not affect protein turnover in pre- and early pubertal female gymnasts. Eur J Appl Physiol. 2005;94(3):262-7. https://doi.org/ 10.1007/s00421-004-1264-5.

38. Beckett PR, Jahoor F, Copeland KC. The efficiency of dietary protein utilization is increased during puberty. J Clin Endocrinol Metab. 1997;82(8):2445-9. https://doi.org/10.1210/jcem.82.8. 4158.

39. Mazzulla M, Volterman KA, Packer JE, Wooding DJ, Brooks $\mathrm{JC}$, Kato $\mathrm{H}$, et al. Whole-body net protein balance plateaus in response to increasing protein intakes during post-exercise recovery in adults and adolescents. Nutr Metab (Lond). 2018;15:62. https://doi.org/10.1186/s12986-018-0301-z.

40. Aerenhouts D, Van Cauwenberg J, Poortmans JR, Hauspie R, Clarys P. Influence of growth rate on nitrogen balance in adolescent sprint athletes. Int J Sport Nutr Exerc Metab. 2013;23(4):409-17.

41. Gleeson M. Biochemistry of exercise. In: Maughan R, editor. Nutrition in sport: IOC Medical Commission; 2000. p. 17-38.

42. Burke LM, van Loon LJC, Hawley JA. Postexercise muscle glycogen resynthesis in humans. J Appl Physiol (1985). 2017;122(5):1055-67. https://doi.org/10.1152/japplphysiol. 00860.2016

43. Rothschild JA, Kilding AE, Plews DJ. What should I eat before exercise? Pre-exercise nutrition and the response to endurance exercise: current perspective and future directions. Nutrients. 2020;12(11):3473. https://doi.org/10.3390/nu12113473.

44. Desbrow B, Leveritt M. Nutritional issues for young athletes: children and adolescents. In: Burke LM, Deakin V, Minehan M, editors. Clinical sports nutrition. 6th ed. McGraw Hill; 2020.

45. Goodpaster BH, Wolfe RR, Kelley DE. Effects of obesity on substrate utilization during exercise. Obes Res. 2002;10(7):575-84. https://doi.org/10.1038/oby.2002.78.

46. Chu L, Morrison KM, Riddell MC, Raha S, Timmons BW. Metabolic flexibility during exercise in children with obesity and matched controls. Med Sci Sports Exerc. 2021;53(1):159-64. https://doi.org/10.1249/MSS.0000000000002428.

47. de Ataid e Silva T, Di Cavalcanti Alves Souza ME, de Amorim JF, Stathis CG, Leandro CG, Lima-Silva AE. Can carbohydrate mouth rinse improve performance during exercise? A systematic review. Nutrients. 2013;6(1):1-10. https://doi.org/10.3390/nu601 0001.

48. Burke LM, Hawley JA, Wong SH, Jeukendrup AE. Carbohydrates for training and competition. J Sports Sci. 2011;29(Suppl 1):S1727. https://doi.org/10.1080/02640414.2011.585473.

49. Randell RK, Rollo I, Roberts TJ, Dalrymple KJ, Jeukendrup AE, Carter JM. Maximal fat oxidation rates in an athletic population. Med Sci Sports Exerc. 2017;49(1):133-40. https://doi.org/10. 1249/MSS.0000000000001084.

50. National Health and Medical Research Council. The Australian Guide to Healthy Eating. 2017 [cited 26 Jun 2019]. https://www. eatforhealth.gov.au/guidelines/australian-guide-healthy-eating. Accessed 18 Aug 2021.

51. Department of Agriculture, Department of Health and Human Services. Dietary Guidelines for Americans, 2020-2025. 9th ed. Washington, DC; 2020. p. 75-88. https://DietaryGuidelines.gov. Accessed 18 Aug 2021.

52. Burke LM, Castell LM, Casa DJ, Close GL, Costa RJS, Desbrow $\mathrm{B}$, et al. International Association of Athletics Federations Consensus Statement 2019: nutrition for athletics. Int J Sport Nutr Exerc Metab. 2019;29(2):73-84. https://doi.org/10.1123/ijsnem. 2019-0065.

53. Impey SG, Hearris MA, Hammond KM, Bartlett JD, Louis J, Close GL, et al. Fuel for the work required: A theoretical framework for carbohydrate periodization and the glycogen threshold hypothesis. Sports Med. 2018;48(5):1031-48. https://doi.org/10. 1007/s40279-018-0867-7. 
54. Reguant-Closa A, Harris MM, Lohman TG, Meyer NL. Validation of the Athlete's Plate nutrition educational tool: phase I. Int J Sport Nutr Exerc Metab. 2019;29(6):628-35. https://doi.org/10. 1123/ijsnem.2018-0346.

55. Shoemaker ME, Gillen ZM, McKay BD, Koehler K, Cramer JT. High prevalence of poor iron status among 8- to 16-year-old youth athletes: Interactions among biomarkers of Iron, dietary intakes, and biological maturity. J Am Coll Nutr. 2020;39(2):155-62. https://doi.org/10.1080/07315724.2019.1621229.

56. Malczewska-Lenczowska J, Orysiak J, Szczepanska B, Turowski D, Burkhard-Jagodzinska K, Gajewski J. Reticulocyte and erythrocyte hypochromia markers in detection of iron deficiency in adolescent female athletes. Biol Sport. 2017;34(2):111-8. https:// doi.org/10.5114/biolsport.2017.64584.

57. Peeling P, Deakin V. Prevention, detection and treatment of iron depletion. In: Burke LM, Deakin V, Minehan M, editors. Clinical Sports Nutrition. 6th ed. McGraw Hill Education Australia; 2021.

58. Peeling P, Blee T, Goodman C, Dawson B, Claydon G, Beilby J, et al. Effect of iron injections on aerobic-exercise performance of iron-depleted female athletes. Int J Sport Nutr Exerc Metab. 2007;17(3):221-31.

59. AIS. AIS Sports Supplement Framework: Iron Supplement. 2019. https://www.ais.gov.au/nutrition/supplements/group_a\#iron. Accessed 18 Aug 2021.

60. Okazaki K, Stray-Gundersen J, Chapman RF, Levine BD. Iron insufficiency diminishes the erythropoietic response to moderate altitude exposure. J Appl Physiol (1985). 2019;127(6):1569-78. https://doi.org/10.1152/japplphysiol.00115.2018.

61. Shoemaker ME, Gillen ZM, McKay BD, Bohannon NA, Gibson SM, Koehler K, et al. Sex-specific relationships among iron status biomarkers, athletic performance, maturity, and dietary intakes in pre-adolescent and adolescent athletes. J Int Soc Sports Nutr. 2019;16(1):42. https://doi.org/10.1186/s12970-019-0306-7.

62. Gropper SS, Blessing D, Dunham K, Barksdale JM. Iron status of female collegiate athletes involved in different sports. Biol Trace Elem Res. 2006;109(1):1-14. https://doi.org/10.1385/BTER: 109:1:001.

63. Koehler K, Braun H, Achtzehn S, Hildebrand U, Predel HG, Mester $\mathbf{J}$, et al. Iron status in elite young athletes: genderdependent influences of diet and exercise. Eur J Appl Physiol. 2012;112(2):513-23. https://doi.org/10.1007/s00421-011-2002-4.

64. SCAN. Scientific advisory committee on nutrition: iron and health. London: British Government; 2010. p. 374.

65. Matkovic V. Calcium metabolism and calcium requirements during skeletal modeling and consolidation of bone mass. Am J Clinical Nutr. 1991;54(2 Suppl):245S-S260.

66. Weeks BK, Young CM, Beck BR. Eight months of regular inschool jumping improves indices of bone strength in adolescent boys and girls: the POWER PE study. J Bone Miner Res. 2008;23(7):1002-11.

67. Stear SJ, Prentice A, Jones SC, Cole TJ. Effect of a calcium and exercise intervention on the bone mineral status of 16-18-y-old adolescent girls. Am J Clin Nutr. 2003;77(4):985-92.

68. Elhakeem A, Heron J, Tobias JH, Lawlor DA. Physical activity throughout adolescence and peak hip strength in young adults. JAMA Netw Open. 2020;3(8):e2013463. https://doi.org/10.1001/ jamanetworkopen.2020.13463.

69. de la Puente YM, Collado Yurrita L, Ciudad Cabanas MJ, Cuadrado Cenzual MA. Role of Vitamin D in athletes and their performance: current concepts and new trends. Nutrients. 2020;12(2):579. https://doi.org/10.3390/nu12020579.

70. Orysiak J, Mazur-Rozycka J, Fitzgerald J, Starczewski M, Malczewska-Lenczowska J, Busko K. Vitamin D status and its relation to exercise performance and iron status in young ice hockey players. PLoS ONE. 2018;13(4):e0195284. https://doi.org/10.1371/journ al.pone. 0195284 .
71. Bezuglov E, Tikhonova A, Zueva A, Khaitin V, Lyubushkina A, Achkasov E, et al. The dependence of running speed and muscle strength on the serum concentration of Vitamin D in young male professional football players residing in the Russian Federation. Nutrients. 2019;11(9):1960. https://doi.org/10.3390/nu11091960.

72. Rowland T, Hagenbuch S, Pober D, Garrison A. Exercise tolerance and thermoregulatory responses during cycling in boys and men. Med Sci Sports Exerc. 2008;40(2):282-7.

73. Inbar O, Morris N, Epstein Y, Gass G. Comparison of thermoregulatory responses to exercise in dry heat among prepubertal boys, young adults and older males. Exp Physiol. 2004;89(6):691-700.

74. Falk B, Dotan R. Children's thermoregulation during exercise in the heat: a revisit. Appl Physiol Nutr Metab. 2008;33:420-7.

75. Barnes KA, Anderson ML, Stofan JR, Dalrymple KJ, Reimel AJ, Roberts TJ, et al. Normative data for sweating rate, sweat sodium concentration, and sweat sodium loss in athletes: an update and analysis by sport. J Sports Sci. 2019;37(20):2356-66. https://doi. org/10.1080/02640414.2019.1633159.

76. Roche D, Rowland T, Garrard M, Marwood S, Unnithan V. Skin microvascular reactivity in trained adolescents. Eur J Appl Physiol. 2010;108:1201-8.

77. Falk B, Bar-Or O, MacDougall J. Thermoregulatory responses of pre-, mid-, and late-pubertal boys to exercise in dry heat. Med Sci Sports Exerc. 1992;24(6):688-94.

78. Centers for Disease Control Prevention. Nonfatal sports and recreation heat illness treated in hospital emergency departmentsUnited States, 2001-2009. MMWR Morb Mortal Wkly Rep. 2011;60(29):977-80.

79. Somboonwong J, Sanguanrungsirikul S, Pitayanon C. Heat illness surveillance in schoolboys participating in physical education class in tropical climate: an analytical prospective descriptive study. BMJ Open. 2012;2(4):e000741. https://doi.org/10.1136/ bmjopen-2011-000741.

80. Aragon-Vargas L, Wilk B, Timmons B, Bar-Or O. Body weight changes in child and adolescent athletes during a triathlon competition. Eur J Appl Physiol. 2013;113(1):233-9.

81. Bergeron MF. Hydration in the pediatric athlete-how to guide your patients. Curr Sports Med Rep. 2015;14(4):288-93. https:// doi.org/10.1249/JSR.0000000000000179.

82. Rowland T. Fluid replacement requirements for child athletes. Sports Med. 2011;41(4):279-88. https://doi.org/10.2165/11584 320-000000000-00000.

83. McDermott BP, Anderson SA, Armstrong LE, Casa DJ, Cheuvront SN, Cooper L, et al. National Athletic Trainers' Association position statement: fluid replacement for the physically active. J Athl Train. 2017;52(9):877-95. https://doi.org/10.4085/10626050-52.9.02.

84. Maughan RJ, Burke LM, Dvorak J, Larson-Meyer DE, Peeling P, Phillips SM, et al. IOC consensus statement: dietary supplements and the high-performance athlete. Br J Sports Med. 2018;52(7):439-55. https://doi.org/10.1136/bjspo rts-2018-099027.

85. Jagim AR, Kerksick CM. Creatine supplementation in children and adolescents. Nutrients. 2021;13(2):664. https://doi.org/10. 3390/nu13020664.

86. Evans M Jr, Ndetan H, Perko M, Williams R, Walker C. Dietary supplement use by children and adolescents in the United States to enhance sport performance: results of the National Health Interview Survey. J Primary Prev. 2012;33:3-12.

87. McDowall J. Supplement use by young athletes. J Sports Sci Med. 2007;6:337-42.

88. Parnell JA, Wiens KP, Erdman KA. Dietary intakes and supplement use in pre-adolescent and adolescent Canadian athletes. Nutrients. 2016;8(9):526. https://doi.org/10.3390/nu8090526. 
89. Bloodworth A, Petroczi A, Bailey R, Pearce G, McNamee M. Doping and supplementation: the attitudes of talented young athletes. Scand J Med Sci Sports. 2012;22:293-301.

90. Peeling P, Castell LM, Derave W, de Hon O, Burke LM. Sports foods and dietary supplements for optimal function and performance enhancement in track-and-field athletes. Int J Sport Nutr
Exerc Metab. 2019;29(2):198-209. https://doi.org/10.1123/ijsnem.2018-0271.

91. Meyer F, O'Connor H, Shirreffs S. Nutrition for the young athlete. J Sports Sci. 2007;25(Suppl 1):S73-82.

92. International Olympic Committee. Consensus Statement on Sports Nutrition. Lausanne: International Olympic Committee; 2010. 